\title{
The Metabolic Syndrome in Rural UAE: The Effect of Gender, Ethnicity and the Environment in its Prevalence
}

\section{Rodhan Khthir* and Felyn Luz Espina}

Marshall university-school of medicine, Huntington, West Virginia, USA

"Corresponding author: Rodhan Abass khthir, Marshall university-school of medicine, Huntington, West Virginia, USA, Tel: 98-411-3357580; E-mail: khthir@marshall.edu

Received date: July 20, 2014; Accepted date: August 20, 2014; Published date: August 25, 2014-08-25

Copyright: (c) 2014 khthir R and Espina FL. This is an open-access article distributed under the terms of the Creative Co mmons Attribution License, which permits unrestricted use, distribution, and reproduction in any medium, provided the original author and source are credited.

\section{Abstract}

Objective: The purpose of this study was to examine the prevalence of the metabolic syndrome and its individual components among multiethnic population in a rural area in the Western region of Abu Dhabi in The United Arab Emirates (UAE)

Methods: The analytic sample consisted of 575 adults (males: 309, females: 266), between the age of 22 and 65 years. The National Cholesterol Education Program's Adult Treatment Panel III (NCEP/ATP III) guidelines (with race specific abdominal circumference cutoff level) were used to identify adults who met their criteria for metabolic syndrome with. Prevalence estimates were calculated for each component of the metabolic syndrome in addition to the overall prevalence of metabolic syndrome. Prevalence estimates were analyzed by sex, ethnicity and working hours.

Results: Approximately $22 \%$ of adults met the criteria for metabolic syndrome. The prevalence was $26 \%$ in Males and $14 \%$ in females, P. Value $<0.01$. The prevalence was $16 \%$ among South East Asians (SEA), $20 \%$ among Arabs (ARB) and $26 \%$ among South Asians (SA), with $P$ value of $0.523,0.075$ and $<0.05$ for ARB versus SEA, ARB versus SA, and SA vs SEA respectively. The prevalence of the metabolic syndrome among night shift workers was $25 \%$ in comparison to $19 \%$ among daytime workers ( $P$ value 0.1 ). The prevalence of the different components of the metabolic syndrome varied by race and ethnicity

Conclusions: These results demonstrate that metabolic syndrome is less prevalent in rural area than inner city population in UAE which was reported to be around $40 \%$ in previous studies possibly because of lifestyle differences. The prevalence varied significantly by race and ethnicity and gender. Night shift work was associated with higher prevalence of the metabolic syndrome in our study but this was not statistically significant.

Keywords Metabolic syndrome; Abdominal obesity; Blood pressure; Diabetes

\section{Introduction}

The metabolic syndrome is the co-occurrence of multiple metabolic abnormalities (abdominal obesity, hyperglycemia, dyslipidemia, and hypertension). These metabolic abnormalities are considered metabolic risk factors for both type 2 diabetes and cardiovascular disease. Prospective observational studies demonstrate a strong association between the metabolic syndrome and the risk for subsequent development of type 2 diabetes [1-5]. The metabolic syndrome increased the relative risk (RR) for incident diabetes by 2.1fold with the ATP III definition and 3.6-fold using the WHO definition.

Three meta-analyses, found that the metabolic syndrome increases also the risk for cardiovascular disease (CVD) (RRs ranging from 1.53 to 2.18) and all cause mortality (RRs 1.27 to 1.60 ) [6-8].

Current ATP III criteria define the metabolic syndrome as the presence of any three of the following five traits $[9,10]$ :
- Abdominal obesity, defined as a waist circumference in men $\geq 102$ $\mathrm{cm}$ (40 in) and in women $\geq 88 \mathrm{~cm}$ (35 in)

- Serum triglycerides $\geq 150 \mathrm{mg} / \mathrm{dL}(1.7 \mathrm{mmol} / \mathrm{L})$ or drug treatment for elevated triglycerides

- Serum HDL cholesterol $<40 \mathrm{mg} / \mathrm{dL}(1 \mathrm{mmol} / \mathrm{L})$ in men and $<50$ $\mathrm{mg} / \mathrm{dL}(1.3 \mathrm{mmol} / \mathrm{L})$ in women or drug treatment for low HDL-C

- Blood pressure $\geq 130 / 85 \mathrm{mmHg}$ or drug treatment for elevated blood pressure

- Fasting plasma glucose $(\mathrm{FPG}) \geq 100 \mathrm{mg} / \mathrm{dL}(5.6 \mathrm{mmol} / \mathrm{L})$ or drug treatment for elevated blood glucose

According to ATP III, a diagnosis of the metabolic syndrome is made when three or more of the risk factors. In 2009, a new cut point was suggested for South Asians and South East Asians (Chinese/ Japanese population) [11].

The metabolic syndrome is becoming increasingly common. Using data from the National Health and Nutrition Examination Survey 1999 to 2002 database, 34.5 percent of participants met ATP III criteria for the metabolic syndrome compared with 22 percent in NHANES III (1988 to 1994) [12,13]. Racial and gender discrepancy in the prevalence of the metabolic syndrome was described previously. For 
example, the prevalence of the metabolic syndrome, as defined by the 2001 ATP III criteria, was evaluated in 8814 adults in the United States participating in the third National Health and Nutrition Examination Survey (NHANES III, 1988 to 1994) [12]. Mexican-Americans had the highest age-adjusted prevalence (31.9 percent). Among AfricanAmericans and Mexican-Americans, the prevalence was higher in women than in men (57 and 26 percent higher, respectively).

The prevalence of the metabolic syndrome in the United Arab Emirates (UAE) was estimated to be around $40 \%$ based on a single prevalence study done in two big cities. [14]. UAE has a very high prevalence of diabetes and obesity and also has very racially diverse population.

The purpose of this study was to examine the prevalence of the metabolic syndrome in the rural part of the UAE and to study the racial and gender discrepancy in the prevalence of the metabolic syndrome and its different components among multiethnic population in a rural area in the Western region of Abu Dhabi-UAE. The study examined also the association between the metabolic syndrome prevalence and night shift work one of the potential risk factor for the metabolic syndrome and other metabolic disorders.

\section{Methods}

\section{Subjects}

The study is a cross-sectional prevalence study conducted over a period of 4 weeks at Madinat Zayed hospital, a secondary care rural hospital in the Western region of Abu Dhabi. The study population consisted of hospital employees and the study was done during the annual employee health campaign. The surveillance process included healthcare questionnaire, measurement of weight, Height, BMI and abdominal circumference, health examination and laboratory test in fasting state for glucose and lipids.

Height, weight, and waist circumference were all measured using standardized techniques and calibrated equipment. A certified phlebotomist drew fasting morning blood samples from the examinee's arm for the lipid and glucose assays. Standardized techniques were used to obtain the blood pressure measurements. Abdominal circumference was measured at standing position with a measurement tape at the level of the upper border of the anterior superior iliac crest. Weight and height measurement were done by standard electronic machines that computed the BMI directly.

Pregnant females and participants with incomplete data were deleted from the analytic sample. The final analytic sample consisted of 575 adults (males: 309, females: 266), between the age of 22 and 65 years.

\section{Definition of metabolic syndrome}

The NCEP/ATP III revised guidelines (see introduction) were used to identify adults in the analytic sample who had metabolic syndrome. In addition, individuals who reported currently taking antihypertensive medication were classified as having high blood pressure and individuals currently taking insulin or an oral diabetic medication were classified as having diabetes. According to these guidelines, metabolic syndrome is defined as the presence of three or more of these risk factors.
BP above 130/85 was confirmed after 5 minutes. The averages of the two systolic and diastolic blood pressure readings were used for the analysis.

Regarding the cutoff level for the waist circumference used, we used $88 \mathrm{~cm}$ for Arab females, $102 \mathrm{~cm}$ for Arab males, and $80 \mathrm{~cm}$ for nonArab females and $90 \mathrm{~cm}$ for non-Arab Males based on the updates 2009 NCEP-ATP 3 definition [11].

\section{Data analyses}

The prevalence of the metabolic syndrome in the whole group was evaluated and stratified by ethnicity, gender, BMI and work shift. The prevalence of the individual component of the metabolic syndrome was reported as well by ethnicity and gender.

BMI was categorized into three groups. These categories were: $>25$ $\mathrm{kg} / \mathrm{m}^{2}, 25-30 \mathrm{~kg} / \mathrm{m}^{2}$, and $>30 \mathrm{~kg} / \mathrm{m}^{2}$.

Results are reported for self-identified Arabs (AR), South Asians (SA) (mainly from India, Pakistan and Bangladish) and South East Asian (SEA) (mainly from the Philippines and Indonesia).

BMI measures relative weight for height. BMI was calculated by dividing weight by height squared $\left(\mathrm{kg} / \mathrm{m}^{2}\right)$. Weight categories were created based on the National Heart, Lung, and Blood Institute's classification system. The underweight and normal weight categories were combined as well as the obese and extremely obese categories because of limited sample sizes. The three categories used in this analysis were underweight and normal weight (BMI less than 25), overweight (BMI 25-29.9), and obese and extremely obese (BMI 30 or greater).

Differences in continuous data between the two groups were evaluated using the t-test. Differences between categorical data were compared using chi-square test. $\mathrm{P}$ value $<0.05$ was considered statistically significant. Statistical analysis was performed using QI Macros 2012.

\section{Results}

The Study population consisted of 309 males and 266 females with 269 South Asians, 195 Arabs and 112 South East Asians. The average age of the study population is 37.96 . The average age for males is 37.1, female $38.66(p=0.03)$. The average age for Arabs is 41.16 , South East Asians is 38.77, and Asians: 34.59 ( $\mathrm{P}$ value was $<0.5$ for all comparisons).

The average age for shift workers is 37.21 and for non-shift workers is 38.75 ( $\mathrm{p}$ value 0.046 ).

The weight distribution varied between Arabs and other groups, with $75 \%$ of Arabs were either overweight or obese versus $35 \%$ in South Asians $(\mathrm{p}<0.01)$ and $39 \%$ in South East Asians $(\mathrm{p}<0.01)$ Figure 1. The prevalence of overweight and obesity were similar between males and females (51\% in both groups) but the prevalence of abdominal obesity was $76 \%$ in females versus $34 \%$ in Males ( $<<0.01)$. 
Page 3 of 5

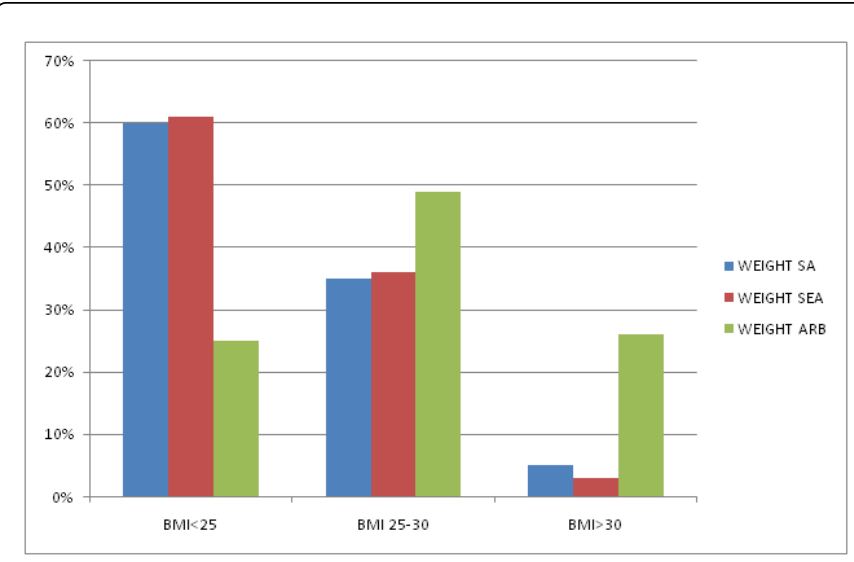

Figure 1: Weight distribution by ethnic group

Approximately 22\% (124/575) of adults met the criteria for metabolic syndrome. Abdominal obesity (53\%), low HDL (34\%), high triglyceride (21\%) and hyperglycemia (20\%) were the most frequently occurring risk factors for metabolic syndrome (Figure 2).

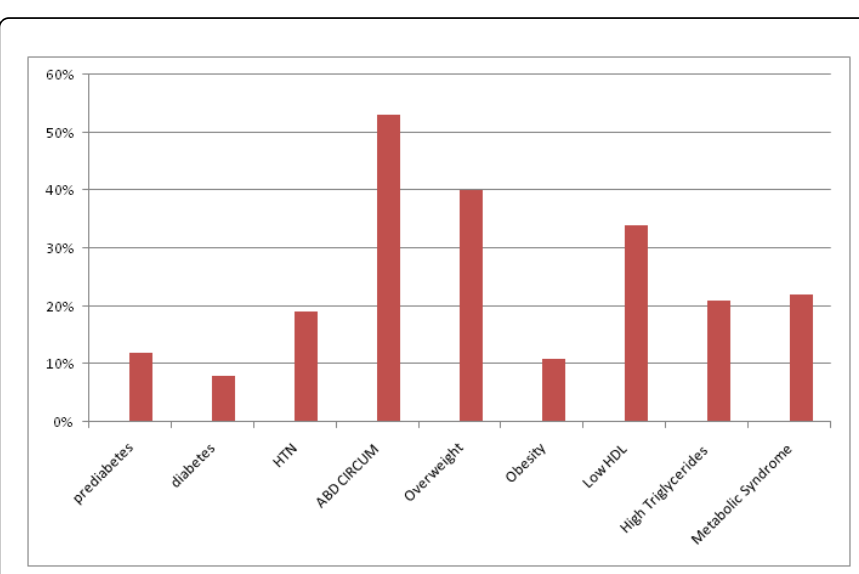

Figure 2: The prevalence of the metabolic syndrome and its components in the study population.

The prevalence of the metabolic syndrome was $26 \%$ in Males $(81 / 309)$ and $14 \%$ in females $(36 / 266), P$. Value $<0.01$. The prevalence was 16\% (18/112) among South East Asians, 20\% (37/195) among Arabs and 26\% (69/269) among South Asians. (P value 0.523, 0.075 and $<0.05$ for $A R B$ versus SEA, ARB versus SA, and SA versus SEA respectively).

The prevalence of hyperglycemia was $15 \%$ (17/112) in Southeast Asians, 26\% (52/195) among Arabs and 18\% (47/265) among South Asian. The prevalence of HTN was 16\% (18/112) in Southeast Asians, 8\% (16/195) among Arabs and 28\% (75/265) among South Asian. The prevalence of abdominal obesity was 63\% (71/112) in Southeast Asians, 51\% (100/195) among Arabs and 51\% (136/265) among South Asian. For HDL abnormality, the prevalence was 20\% (22/112) in Southeast Asians, 34\% (67/195) among Arabs and 40\% (105/265) among South Asian and the prevalence of hypertriglyceridemia was $18 \%(20 / 112)$ in Southeast Asians, 18\% (36/195) among Arabs and $23 \%(62 / 265)$ among South Asians. There was a statistically significant difference between the groups except for hypertriglyceridemia (Table $1)$.

\begin{tabular}{|l|l|l|l|l|l|l|}
\hline & $\begin{array}{l}\text { South } \\
\text { East } \\
\text { Asians } \\
\text { (SEA) }\end{array}$ & $\begin{array}{l}\text { Arabs } \\
\text { (ARB) }\end{array}$ & $\begin{array}{l}\text { South } \\
\text { Asians } \\
\text { (SA) }\end{array}$ & $\begin{array}{l}\text { P value } \\
\text { SEA vs } \\
\text { ARB }\end{array}$ & $\begin{array}{l}\text { P value } \\
\text { SEA vs } \\
\text { SA }\end{array}$ & $\begin{array}{l}\text { P value } \\
\text { SA vs } \\
\text { ARB }\end{array}$ \\
\hline Hyperglycemia & $15 \%$ & $26 \%$ & $18 \%$ & 0.02 & 0.02 & 0.5 \\
\hline HTN & $16 \%$ & $8 \%$ & $28 \%$ & 0.049 & 0.015 & $<0.001$ \\
\hline $\begin{array}{l}\text { Abdominal } \\
\text { obesity }\end{array}$ & $63 \%$ & $51 \%$ & $51 \%$ & 0.039 & 0.031 & 0.99 \\
\hline Low HDL & $20 \%$ & $34 \%$ & $40 \%$ & 0.006 & $<0.001$ & 0.248 \\
\hline $\begin{array}{l}\text { High } \\
\text { Triglycerides }\end{array}$ & $18 \%$ & $18 \%$ & $23 \%$ & 0.89 & 0.233 & 0.2 \\
\hline
\end{tabular}

Table 1: Racial discrepancy in the prevalence of the different component of the metabolic syndrome (statistical analysis)

The prevalence of the metabolic syndrome among night shift workers was $25 \%(54 / 215)$ in comparison to $19 \%$ (70/360) among daytime workers. $\mathrm{P}$ value didn't reach statistical significance.

\section{Discussion}

Based on the NCEP/ATP III guidelines, a little more than $20 \%$ of the adults in the study group could be characterized as having metabolic syndrome. These results demonstrate that metabolic syndrome is less prevalent in rural area than inner city population in UAE which was reported to be around $40 \%$ in previous studies possibly because of life style differences. The prevalence of metabolic syndrome varied by race and ethnicity with the highest prevalence was among South Asians in spite of having a lower prevalence of obesity than Arab population and similar weight distribution to South East Asians. This paradox is most likely related to genetic and environmental factors that predispose South Asians to higher prevalence of hypertension, hypertriglyceridemia and low HDL level at lower BMI. In our study the prevalence of the metabolic syndrome was $10 \%$ in South Asians with BMI of $<23 \mathrm{~kg} / \mathrm{m}^{2}$ reaching to $58 \%$ in the same group as BMI increase in the obesity range $(>30) \mathrm{kg} / \mathrm{m}^{2}$ while in Arabs the prevalence of the metabolic syndrome in normal weight population was $3 \%$, reaching only to $36 \%$ in obese population.

It should be noted that the mean age of South Asians was lower than other Ethnic groups and this should have predicted lower prevalence rate as there is a positive association between age and the prevalence of the metabolic syndrome.

The sharp increase in the prevalence of the metabolic syndrome in obese South Asians and the relatively high prevalence at normal BMI need further studies in a larger cohort and further evaluation of the current BMI cut-off levels in that population (Figure 3). 
Citation: Khthir R, Espina FL (2014) The Metabolic Syndrome in Rural UAE: The Effect of Gender, Ethnicity and the Environment in its Prevalence. J Metabolic Synd 3: 159. doi:10.4172/2167-0943.1000159

Page 4 of 5

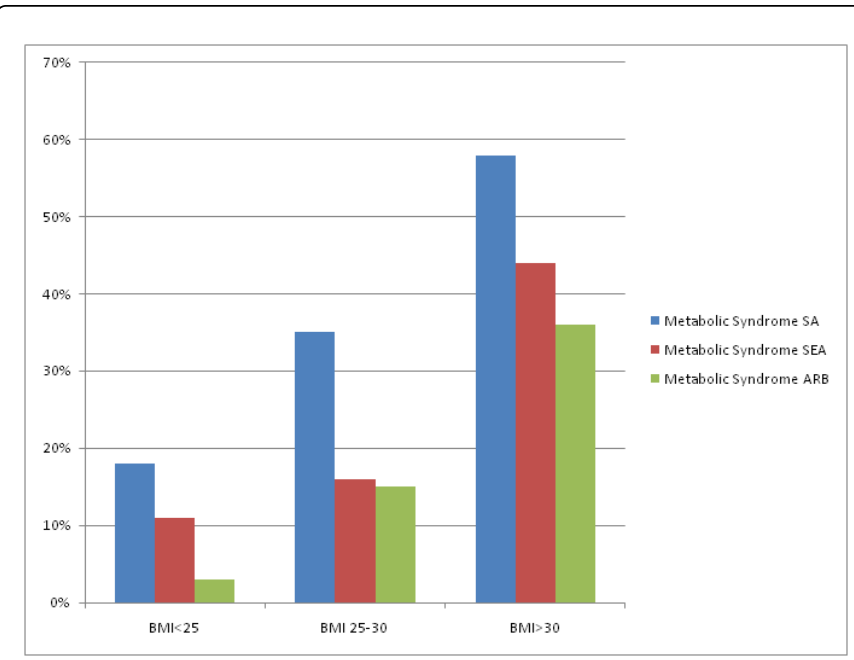

Figure 3: The prevalence of the metabolic syndrome among different ethnicities according to the weight category

The prevalence varied significantly also by sex with significantly lower prevalence among females in spite of the very high prevalence of abdominal obesity among females and in spite of having higher mean age than males. The very high prevalence of abdominal obesity in certain racial group didn't predict higher prevalence of the metabolic syndrome (Figure 4).

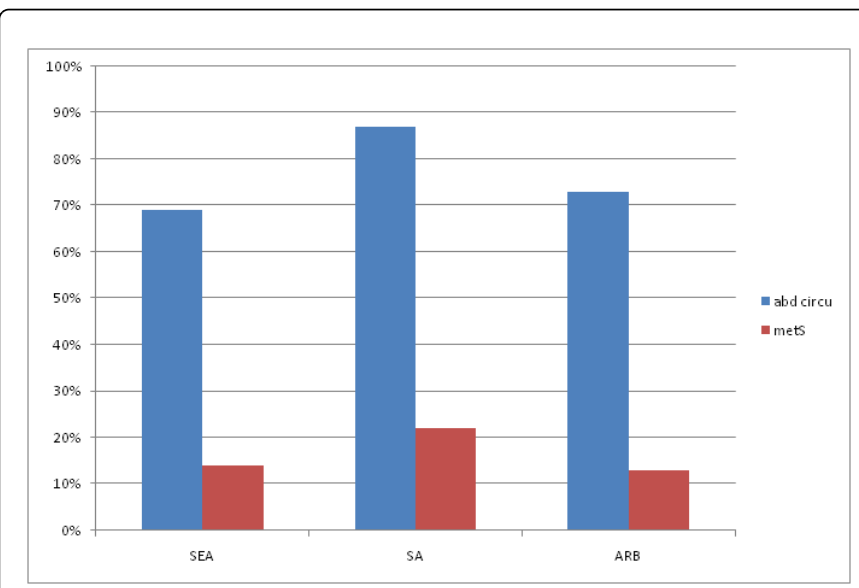

Figure 4: Abdominal Circumference and the Metabolic Syndrome in Females

This may suggest that the current race based cut-off level need to be re-examined. While in males the correlation between prevalence of abdominal obesity and the metabolic syndrome was stronger especially in South Asians (Figure 5).

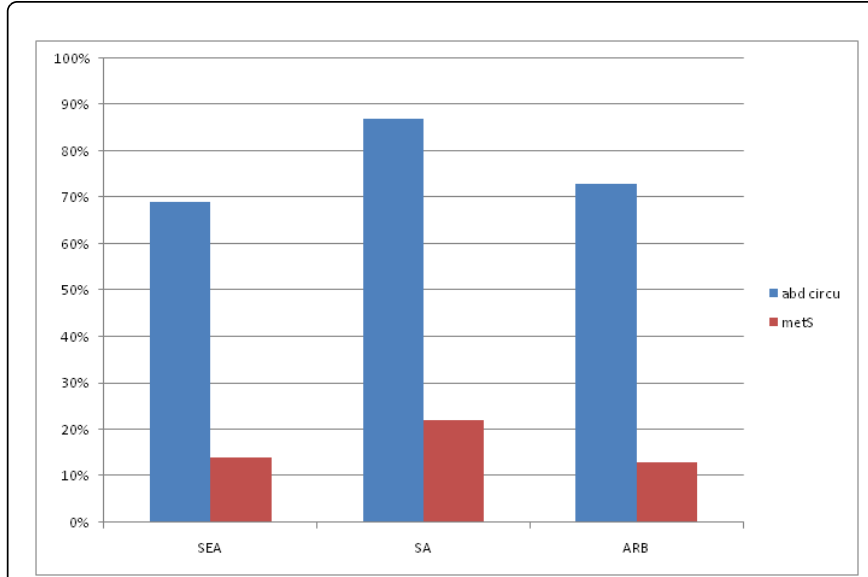

Figure 5: Abdominal Circumference and the Metabolic Syndrome in Males

Finally, Night shift work was associated with higher prevalence of the metabolic syndrome in our study but this didn't reach statistical significance. It should be noted that shift workers has lower mean age. Our study was not powered to detect such difference and more research is needed to explore the importance of night shift work as a potential risk factor for metabolic abnormalities.

\section{References}

1. Hanson RL, Imperatore G, Bennett PH, Knowler WC (2002) Components of the "metabolic syndrome" and incidence of type 2 diabetes. Diabetes 51: 3120-3127.

2. Resnick HE, Jones K, Ruotolo G, Jain AK, Henderson J, et al. (2003) Insulin resistance, the metabolic syndrome, and risk of incident cardiovascular disease in nondiabetic american indians: the Strong Heart Study. Diabetes Care 26: 861-867.

3. Klein BE, Klein R, Lee KE (2002) Components of the metabolic syndrome and risk of cardiovascular disease and diabetes in Beaver Dam. Diabetes Care 25: 1790-1794.

4. Sattar N, Gaw A, Scherbakova O, Ford I, O'Reilly DS, et al. (2003) Metabolic syndrome with and without C-reactive protein as a predictor of coronary heart disease and diabetes in the West of Scotland Coronary Prevention Study. Circulation 108: 414-419.

5. Sattar N, McConnachie A, Shaper AG, Blauw GJ, Buckley BM, et al. (2008) Can metabolic syndrome usefully predict cardiovascular disease and diabetes? Outcome data from two prospective studies. Lancet 371: 1927-1935.

6. Ford ES (2005) Risks for all-cause mortality, cardiovascular disease, and diabetes associated with the metabolic syndrome: a summary of the evidence. Diabetes Care 28: 1769-1778.

7. Galassi A, Reynolds K, He J (2006) Metabolic syndrome and risk of cardiovascular disease: a meta-analysis. Am J Med 119: 812-819.

8. Gami AS, Witt BJ, Howard DE, Erwin PJ, Gami LA, et al. (2007) Metabolic syndrome and risk of incident cardiovascular events and death: a systematic review and meta-analysis of longitudinal studies. J Am Coll Cardiol 49: 403-414.

9. Expert Panel on Detection, Evaluation, and Treatment of High Blood Cholesterol in Adults (2001) Executive Summary of The Third Report of The National Cholesterol Education Program (NCEP) Expert Panel on Detection, Evaluation, And Treatment of High Blood Cholesterol In Adults (Adult Treatment Panel III). JAMA 285: 2486-2497.

10. Grundy SM, Cleeman JI, Daniels SR, Donato KA, Eckel RH, et al. (2005) Diagnosis and management of the metabolic syndrome: an American 
Citation: Khthir R, Espina FL (2014) The Metabolic Syndrome in Rural UAE: The Effect of Gender, Ethnicity and the Environment in its Prevalence. J Metabolic Synd 3: 159. doi:10.4172/2167-0943.1000159

Page 5 of 5

Heart Association/National Heart, Lung, and Blood Institute Scientific Statement. Circulation 112: 2735-2752.

11. Alberti KG, Eckel RH, Grundy SM, (2009) Harmonizing the metabolic syndrome: a joint interim statement of the International Diabetes Federation Task Force on Epidemiology and Prevention; National Heart, Lung, and Blood Institute; American Heart Association; World Heart Federation; International Atherosclerosis Society; and International Association for the Study of Obesity. Circulation 120:1640

12. Ford ES, Giles WH, Dietz WH (2002) Prevalence of the metabolic syndrome among US adults: findings from the third National Health and Nutrition Examination Survey. JAMA 287: 356-359.
13. Ford ES (2005) Prevalence of the metabolic syndrome defined by the International Diabetes Federation among adults in the U.S. Diabetes Care 28: 2745-2749.

14. Malik M, Razig SA (2008) The prevalence of the metabolic syndrome among the multiethnic population of the United Arab Emirates: a report of a national survey. Metab Syndr Relat Disord 6: 177-186. 